\title{
Synthesis of Temperature- and pH-Sensitive Graft Copolymer Containing 2-(Diethylamino)ethyl Methacrylate and N-Vinylcaprolactam onto Silicone Rubber
}

\author{
Alejandra Jiménez-Morales, Alejandro Ramos-Ballesteros, Emilio Bucio* \\ Departamento de Química de Radiaciones y Radioquímica, Instituto de Ciencias Nucleares, Universidad \\ Nacional Autónoma de México, Circuito Exterior, Ciudad Universitaria, México DF, México \\ Email:"ebucio@nucleares.unam.mx
}

Received 21 June 2016; accepted 12 August 2016; published 15 August 2016

Copyright (C) 2016 by authors and Scientific Research Publishing Inc.

This work is licensed under the Creative Commons Attribution International License (CC BY).

http://creativecommons.org/licenses/by/4.0/

c) (i) Open Access

\section{Abstract}

Silicone rubber films were modified by the consecutive grafting of 2-(diethylamino)ethyl methacrylate (DEAEMA) and N-vinylcaprolactam (NVCL) using direct method on two steps with gamma-rays. The effect of absorbed dose and monomer concentration on grafting degree was determined. The grafted samples were verified by FTIR-ATR spectroscopy and swelling; thermal properties were analyzed by DSC and TGA. The stimuli-responsive behavior was studied by swelling and/or DSC. Thermo- and pH-sensitive films of (PP- $g$-DEAEMA)- $g$-NVCL presented a $\mathrm{pH}$ critical at 3.2 and LCST around $63.5^{\circ} \mathrm{C}$.

\section{Keywords}

Radiation-Grafting, Smart Polymers, 2-(Diethylamino)ethyl Methacrylate, N-Vinylcaprolactam

\section{Introduction}

Currently, treatment of diseases and injuries is focused not only in synthesis of new drugs or enhancing of existents, but also in the development of more and better biomaterials suitable for the manufacture of prostheses and medical devices [1]. Common examples include sutures, needles, catheters, plates, tooth fillings, and so on [2].

\footnotetext{
${ }^{*}$ Corresponding author.
} 
An accepted definition of biomaterial is "any substance or combination of substances of synthetic or natural origin that can be used for any period of time, as a whole or as a part of a system which treats, augments, or replaces any tissue, organ or function of the body without causing local adverse reaction or systemic toxicity. Biomaterials thus could either be implanted for long or short term applications, or used externally" [3]. Due to this "required interaction" with biological systems, biomaterials must possess safety and biocompatibility, i.e., must be composed of non-toxic materials and its degradation products should be biodegradable or can generate health affectations [4]. The main problems to overcome by a biomaterial for its effective implementation are: attack by the immune system of the body, toxicity, allergic reactions, irritation of the surrounding structures, abnormal inflammatory response and cause cancer; besides, the material should be economic, reliable and durable [5] [6]. Problems of infection tend to be exacerbated in the presence of biomaterials, since the implant can provide a region inaccessible to immunologically competent cells of the body.

Great efforts have been made to the synthesis and manufacture of biomaterials with different properties according to the required application. Since the first time a synthetic material for wound treatment was used during the World War II, biomaterials have become more sophisticated with specific properties always trying to improve durability, manufacturability and damage reduction to the host organism.

The performance of polymeric materials relies largely upon the properties at the boundaries. Polymeric materials generally have a hydrophobic and chemically inert surface. Untreated non-polar polymer surfaces often have adverse problems in adhesion, coating, painting, coloring, lamination, packaging, colloid stabilization, etc. Among modification techniques developed to date, surface grafting has emerged as a simple, useful, and versatile approach to improve surface properties of polymers for a wide variety of applications [7]. It was found that the best way to improve the biocompatibility of the materials is through surface modifications [8].

Grafting a hydrophilic monomer to a hydrophobic matrix, decreases the interface energy of matrix in the aqueous biological environment and reduces the superficial driving force allowing the hydrophobic material have a better affinity with water by introducing active functional groups onto a polymer backbone [9]. Graft copolymerization is a versatile technique used for the modification of structure, shape and size of polymers. The grafting process initiates with the formation of active sites on the polymer backbone. After formation of active sites, monomer(s) to be incorporated interact with the polymer surface to form covalencies and subsequent chain reactions involving the formation of branches. The active sites may be free radicals or ionic chemical groups, which initiate polymerization reaction [10]. Creation of active sites can be developed by various methods such as: initiation by chemical means, thermal, photoradiation, enzymatic grafting and $\gamma$-radiation [11]. Gamma radiation grafting is an attractive method for obtaining a modified material without chemical initiators or other additives that is applicable to nearly all polymer-monomer combinations [12].

The radiation induced grafting has the following advantages over conventional methods of grafting:

- It's simple, accurate, easy to control and a relatively clean process [13].

- Additives or catalysts rarely required [10].

- The local heating can be avoided unlike the chemical method; therefore, the temperature sensitive monomers can be grafted.

- The energy absorption by the substrate begins the process of free radical formation, unlike the chemical method where the radical formation is determined by the chemical initiator.

- No activation energy is required for the initiation of the process, due it is independent of temperature.

- Due to the high penetrating power of the gamma radiation, radical formation uniform manner throughout the substrate is achieved, particularly suitable for grafting in solid matrices [14].

- The graft may be performed at room temperature [15].

As mentioned before, biocompatibility is the most essential aspect to be considered regarding its importance for biomedical materials due to their direct contact with biological components such as blood and tissues, and if we add the possibility of grafting the polymer surfaces with monomers that response to external stimuli, we expanded the scope of the material [16]. "Intelligent" or smart polymers are stimuli-responsive materials which can undergo volume changes in response to changes in temperature, $\mathrm{pH}$, ionic strength of solvent, light or electromagnetic fields [17]. The concept of a "smart" coating is more recent and has been applied to functional coatings that are able to respond to certain stimuli generated by intrinsic or extrinsic events [14]. These unique characteristics are of great interest in drug delivery, cell encapsulation and tissue engineering, gene transfection and sensors [14] [17].

In the particular case of thermo-sensitive polymers, there can be two different responses. If the polymer is so- 
luble below a certain temperature, it is said to have a lower critical solution temperature (LCST). Above the LCST, the material becomes increasingly hydrophobic and insoluble, and a gel is formed. In contrast, polymers that are hydrophobic below a critical temperature and hydrophilic above it are said to have an upper critical solution temperature (UCST) [18]. Water-soluble polymers with an LCST have attracted a great deal of attention in recent years due to their potential applications in biomedicine and biotechnology. Incorporating monomers with swelling-deswelling capabilities depending on the $\mathrm{pH}$ or temperature of the medium, generated synthesis of new materials with various biomedical applications [19]. Several polymers such as poly(acrylamide), poly $(N-$ isopropylacrylamide), and their copolymers, can respond to environmental changes, but presents problems with biocompatibility, which makes them unsuitable as materials with biomedical applications. In contrast, poly $(N-$ vinylcaprolactam), poly (NVCL) arises as a suitable alternative [20].

$N$-vinylcaprolactam (NVCL) is a cyclic vinyl amide with a seven-membered lactam ring, and it can be categorized as a typical non-conjugated monomer that only undergoes radical polymerization (Scheme 1). NVCL is structurally similar to $\mathrm{N}$-vinylpyrrolidone (NVP) in that the alkene p-electrons are not conjugated with the $\mathrm{C}=\mathrm{O}$ functional group [21].
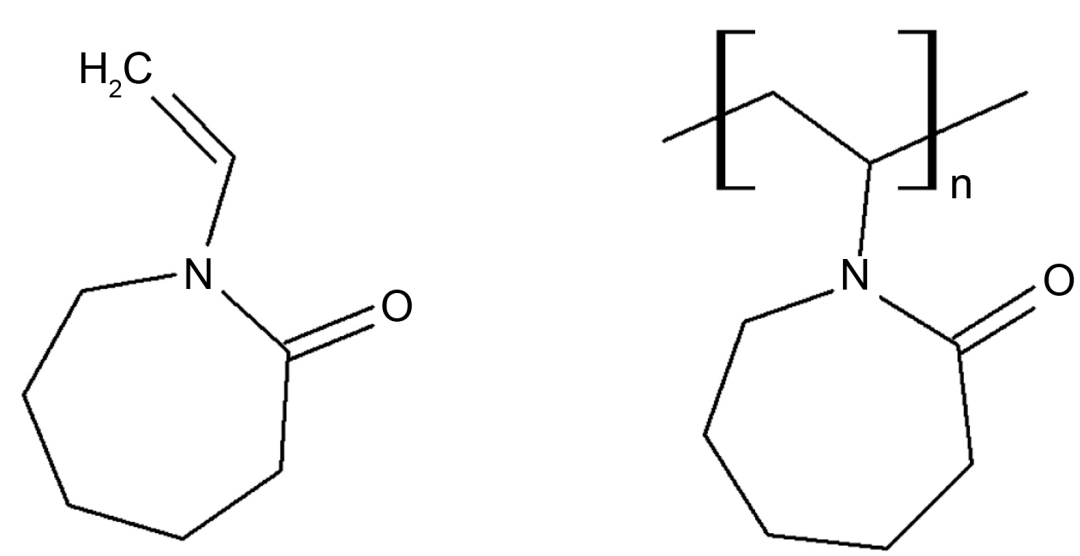

\section{Scheme 1. Molecular structure of $N$-vinylcaprolactam and poly( $N$-vinylcaprolactam).}

Vinylcaprolactam is an amphiphilic monomer because it contains hydrophilic (amide) and hydrophobic (alkyl vinyl group and the lactam ring) groups [22]. The NVCL is partially soluble in water, its solubility is $8.5 \%$ wt. The water solubility of the corresponding homopolymer, poly( $N$-vinylcaprolactam), varies with temperature. The presence of the hydrophobic and hydrophilic groups makes coexist repulsive and attractive forces. The poly ( $N$-vinylcaprolactam) is one of the known thermosensitive polymers. It is nonionic, nontoxic, biocompatible, soluble in water and undergoes a phase separation about $37^{\circ} \mathrm{C}$; LCST near the range of physiological temperature $\left(32-34^{\circ} \mathrm{C}\right)$ [23]. Poly(NVCL) has relatively high resistance to hydrolysis and not produces toxic low molecular weight amines during hydrolysis. These properties make poly (NVCL) suitable for use in some biotechnology such as implantation or purification of enzymes/proteins/living cells, and drug delivery [23].

The radiation polymerization of NVCL already has been reported with thermosensitive properties and low degradation rate on doses beyond $2 \mathrm{kGy}$ (yield of about 90\%) [23]. At high radiation dose rate, the polymerization of NVCL decrease. Crosslinking of the linear chains begin on radiation doses $45 \mathrm{kGy}$ with gel formation > 98\% [23].

The monomer chosen for sensitivity to $\mathrm{pH}$ was $N, N$-diethylaminoethyl methacrylate (DEAEMA). DEAEMA is an ionizable monomer, so $\mathrm{pH}$-sensitive (Scheme 2). A very useful feedstock for chemical syntheses, because it readily undergoes addition reactions with a wide variety of organic and inorganic compounds. The excellent adhesion properties of $N, N$-diethylaminoethyl methacrylate make it ideal as an adhesion promoter for industrial cans and automotive clear coatings. The amine group in $N, N$-diethylaminoethyl methacrylate can be quaternized to give water-soluble ammonium salts used in flocculants or coagulants for water treatment [24]. $N, N$-diethylaminoethyl methacrylate can be used to impart the following properties to polymers: charge introduction possible, impact resistance, adhesion, flexibility and water solubility. On literature is reported a LCST at pH 7 around $40^{\circ} \mathrm{C}$. 


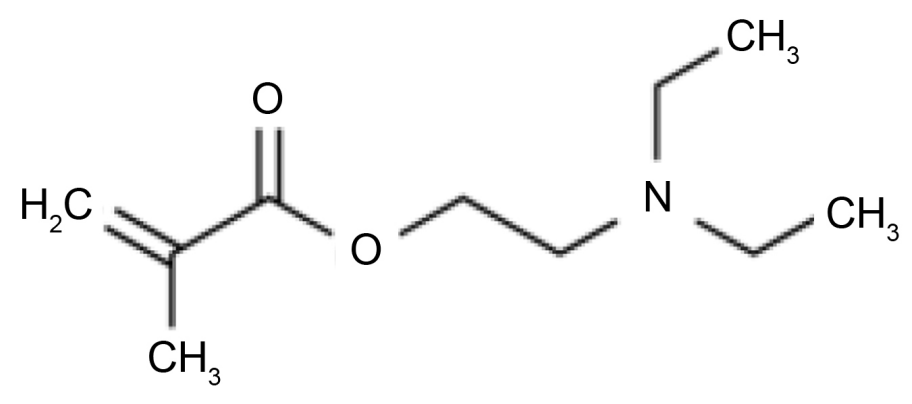

Scheme 2. Molecular structure of $N, N$-diethylaminoethyl methacrylate.

For the radiation induced grafting we used the direct method which consists on the simultaneous irradiation of a polymer with the monomer to be grafted (NVCL and DEAEMA) in a free-oxygen atmosphere. Although this method has the advantage of providing high graft yields, has the disadvantage of simultaneous formation of homopolymer, poly(NVCL) and poly(DEAEMA), this leads to the undesirable consumption of monomer and complicate the pure graft copolymer separation.

As a polymer substrate, silicone is a good candidate for use in monolithic devices where the active agent is dispersed in a polymer matrix and its release is controlled by diffusion from the matrix [25]. Silicone is an important biomaterial used in various biomedical prosthetic purposes, with supplementary mechanical functions in organs such as the trachea or cartilaginous tissues or aesthetic implants [25].

That's why we sought to exploit the advantages of the NVCL (thermo-sensitive) and DEAEMA (pH-sensitive) to generate a binary graft copolymer on silicone rubber by two-step method with swelling-deswelling capabilities. This system retained the mechanical properties of silicone, but with improved biocompatibility by the inclusion of soluble monomers and with fast response to temperature and $\mathrm{pH}$. Because NVCL not shows a high degree of polymerization when synthesized by common methods [20], the polymerization technique used was gamma radiation. The optimum grafting conditions and response to temperature and $\mathrm{pH}$ was evaluated.

\section{Experimental}

\subsection{Materials}

Silicone rubber, SR (1 mm thickness) was obtained from Goodfellow (Huntingdon, UK) and previously washed with ethanol for $24 \mathrm{~h}$ and then dried under reduced pressure. $\mathrm{N}$-vinylcaprolactam and 2-(diethylamino)ethyl methacrylate were purchased from Sigma Aldrich (St. Louis, MO, USA), and distilled under reduced pressure before use. Toluene and ethanol were from J.T. Baker (Mexico) and used as received.

\subsection{Synthesis of (SR- $g$-DEAEMA)- $g$-NVCL by Two Step Method}

SR-g-DEAEMA and (SR-g-DEAEMA)- $g$-NVCL were synthesized placing pieces of SR or SR- $g$-NVCL films (previously weighed) in glass ampoules containing a monomer solution in toluene. The ampoule was degassed by repeated freeze-thaw cycles and sealed. Ampoules were irradiated using a ${ }^{60} \mathrm{Co} \gamma$ source (Gammabeam 651 PT, Nordion International Inc., Canada) at absorbed doses from 10 to $100 \mathrm{kGy}$ and a dose rate of $9.3 \mathrm{kGy} \cdot \mathrm{h}^{-1}$.

\subsection{Purification}

The samples were soaked in ethanol for $24 \mathrm{~h}$ (changed ethanol 2 times), followed by drying under vacuum at $50^{\circ} \mathrm{C}$ to constant weight, in order to extract residual monomer and heteropolymer formed.

\subsection{Grafting Yield}

The grafting yield was calculated according to Equation (1):

$$
\text { Grafting yield }(\%)=\frac{W_{g}-W_{o}}{W_{o}} \times 100
$$


where $W_{g}$ and $W_{o}$ are the weights of the films after and before grafting, respectively.

\subsection{Physical Characterization}

FTIR-ATR spectra of pristine and grafted SR were recorded on ZnSe using a Perkin-Elmer Spectrum 100 spectrometer (Perkin Elmer Cetus Instruments, Norwalk, CT) with 16 scans. Thermal decomposition was recorded in nitrogen atmosphere between 25 and $800^{\circ} \mathrm{C}$ at a heating rate of $10^{\circ} \mathrm{C} \mathrm{min}^{-1}$ using a TGA Q50 (TA Instruments, New Castle, DE). Differential scanning calorimetry (DSC) studies for the determination of thermodynamic transitions were carried out in nitrogen atmosphere using a DSC 2010 calorimeter (TA Instruments, New Castle, DE) from 25 to $300^{\circ} \mathrm{C}$ at a heating rate of $10^{\circ} \mathrm{C} \mathrm{min}^{-1}$. To determine the swelling equilibrium, pieces of polymeric films were immersed into distilled water for different periods of time (from 30 to $900 \mathrm{~min}$ ). The excess of solution on the catheters was removed with filter paper, and the swollen samples were weighed. The swelling percent was determined as follows:

$$
\text { Swelling }(\%)=\left(\frac{W_{s}-W_{d}}{W_{d}}\right) \times 100
$$

where $W_{s}$ and $W_{d}$ represent the weight of the swollen and initial polymeric film, respectively.

\section{6. pH-Responsiveness by Swelling Measurements}

The pH-responsiveness of SR grafted with DEAEMA was determined by measuring the sample's degree of swelling in buffer solutions of $\mathrm{pH}$ ranging from 2 to 10 . The dried sample was exposed to each buffer solution, one at a time, for $24 \mathrm{~h}$ until equilibrium was attained. Afterwards, the sample's surface was gently wiped with filter paper and the swollen sample was weighed. Swelling percentage was determined gravimetrically based on the measured weights of the swollen $\left(W_{s}\right)$ and dried $\left(W_{d}\right)$ films and calculated according to Equation (2). The critical $\mathrm{pH}$ was defined as the inflection point of the swelling (\%) vs. pH plot.

\subsection{Thermo-Responsive Measurement}

The thermo-responsive properties of the films were estimated by means of the lower critical solution temperature, based on the determination of thermodynamic transitions by DSC. The runs of the swollen samples (immersed in distilled water for $24 \mathrm{~h}$ ) were recorded under nitrogen atmosphere using a DSC 2010 calorimeter (TA Instruments, New Castle, DE, USA) using a temperature range of 25 to $80^{\circ} \mathrm{C}$ with a step increase of $1^{\circ} \mathrm{C} \mathrm{min}{ }^{-1}$.

\section{Results and Discussion}

Figure 1 shows the percentage of the DEAEMA grafted onto SR samples as a function of irradiated dose at dose rate of $9.3 \mathrm{kGy} \cdot \mathrm{h}^{-1}$ and monomer concentration of $50 \mathrm{vol} \%$ was examined as a first parameter. The grafting yield increased with irradiation dose; grafting percentages of SR films were 6 and $15 \%$ at 10 and $60 \mathrm{kGy}$, respectively. When irradiation dose exceeded $60 \mathrm{kGy}$, high DEAEMA heteropolymer was formed, and it was difficult to extract the grafted films from the reaction medium (some day was necessary to extract them). However, when the irradiation dose is greater than $50 \mathrm{kGy}$, the recombination of macroradicals becomes predominant and causes that grafting percentage to plateau.

The radiation grafting yield of NVCL onto SR- $g$-DEAEMA ${ }_{(11 \% \text { graft })}$ as function of irradiation dose and monomer concentration 50 vol\%., the effect of the irradiation dose on the grafting yield was examined by two step method at fixed monomer concentrations varying the irradiation dose between 10 and $60 \mathrm{kGy}$. For a 50\% monomer concentration, the grafting yield of poly (NVCL) onto SR films is depicted in Figure 2, where it can be observed that there is an increase in grafting percentage as the irradiation dose increases, which is not unexpected given that the number of latent initiating sites is expected to increase with increasing radiation dose, in all cases, copolymers films were homogenous.

The effect of monomer concentration between 40 and $100 \mathrm{vol} \%$ on the grafting yield was examined. The data plotted in Figure 3 show that a broad range of graft content can be achieved, the efficiency ranging from a quite high minimal value of $10 \%$ graft for poly (NVCL) at monomer concentration $40 \mathrm{vol} \%$, to a saturation value with close to $70 \%$ graft for monomer concentration of 100 vol\%.

Figure 4 shows the relationship between monomer concentration (NVCL in toluene) and grafting yield at a 


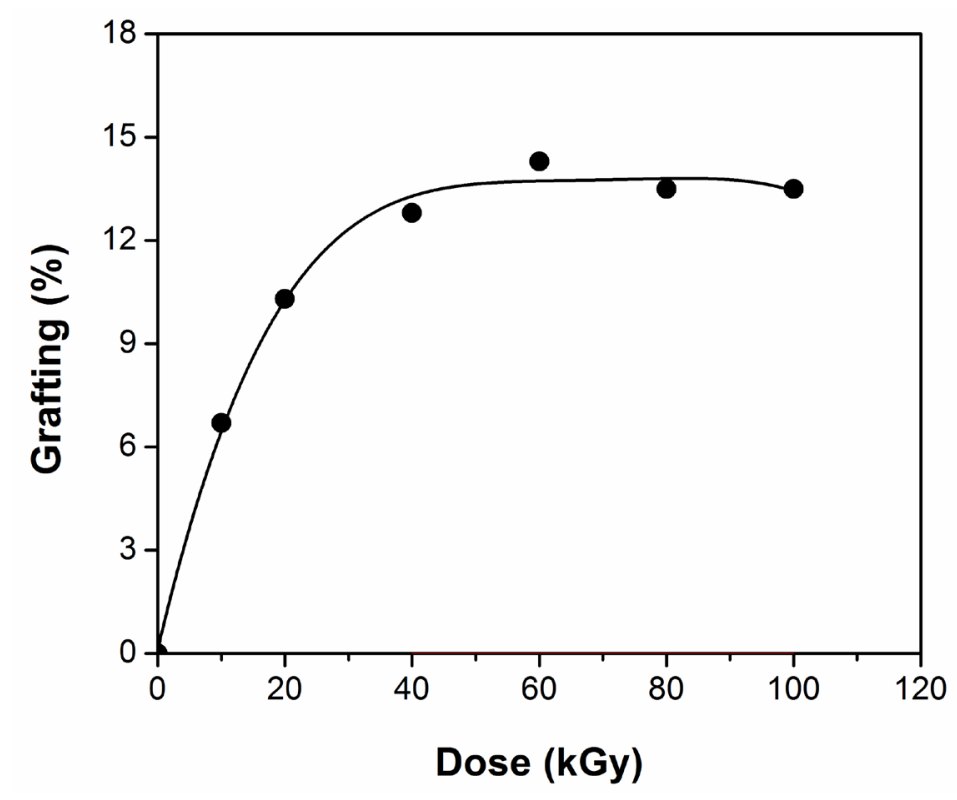

Figure 1. Grafting yield of poly (DEAEMA) onto silicone rubber in toluene as a function of irradiation dose at monomer concentration of $50 \mathrm{vol} \%$.

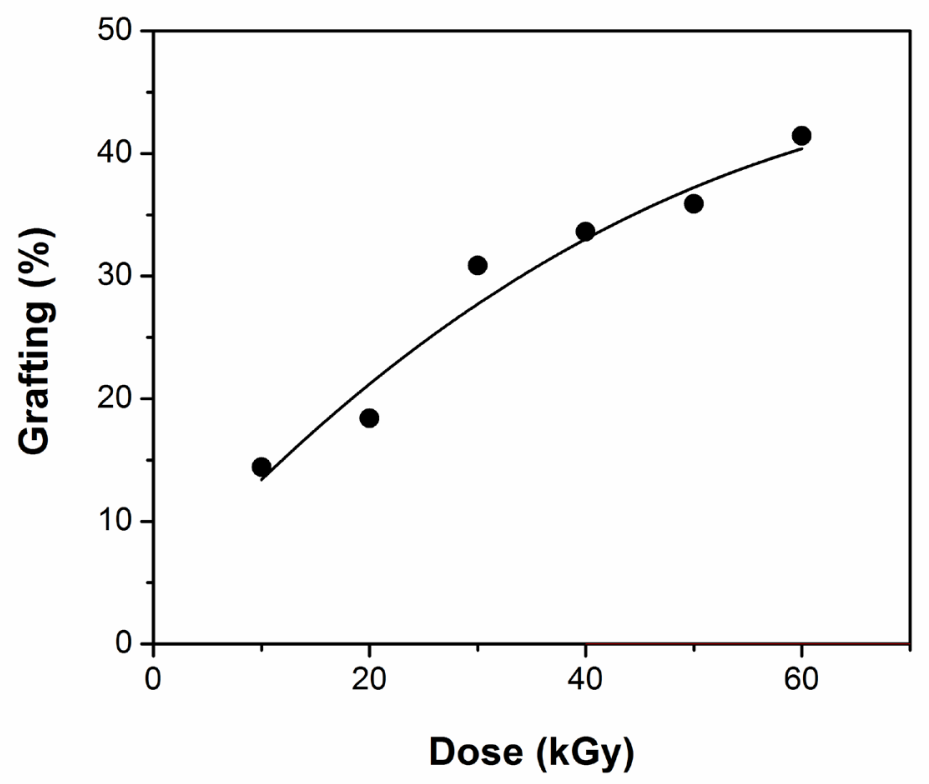

Figure 2. Grafting yield of poly(NVCL) onto SR- $g$-DEAEMA (11\% graft) $_{\text {in }}$ toluene as a function of irradiation dose at monomer concentration of 50 vol\%.

radiation dose of $60 \mathrm{kGy}$ and room temperature, the grafting percentage increases with increasing monomer concentration, reaching maximum of $40 \%$ for a $60 \mathrm{vol} \%$. From the figure it can also be gathered that a higher monomer concentration favors "the gel effect" and crosslinking, which results in slower termination step due to the lack of mobility of the growing chains, and increase in the grafting yield.

FT-IR spectra of SR and graft copolymer (SR- $g$-DEAEMA)- $g$-NVCL at different grafting yields are shown in Figure 5. The spectrum of pristine SR film showed a band at $1005 \mathrm{~cm}^{-1}$ due to stretching vibration of the Si-O-Si bond, and signals at 2963 and $1258 \mathrm{~cm}^{-1}$ which corresponded to $\mathrm{C}-\mathrm{H}$ groups in $\mathrm{CH}_{3}$ and $\mathrm{Si}-\mathrm{CH}_{3}$ respectively (Figure 5(a)). On the other hand, SR-g-DEAEMA showed $\mathrm{C}=\mathrm{O}$ at $1729 \mathrm{~cm}^{-1}$ (Figure 5(b)); poly(NVCL) onto 


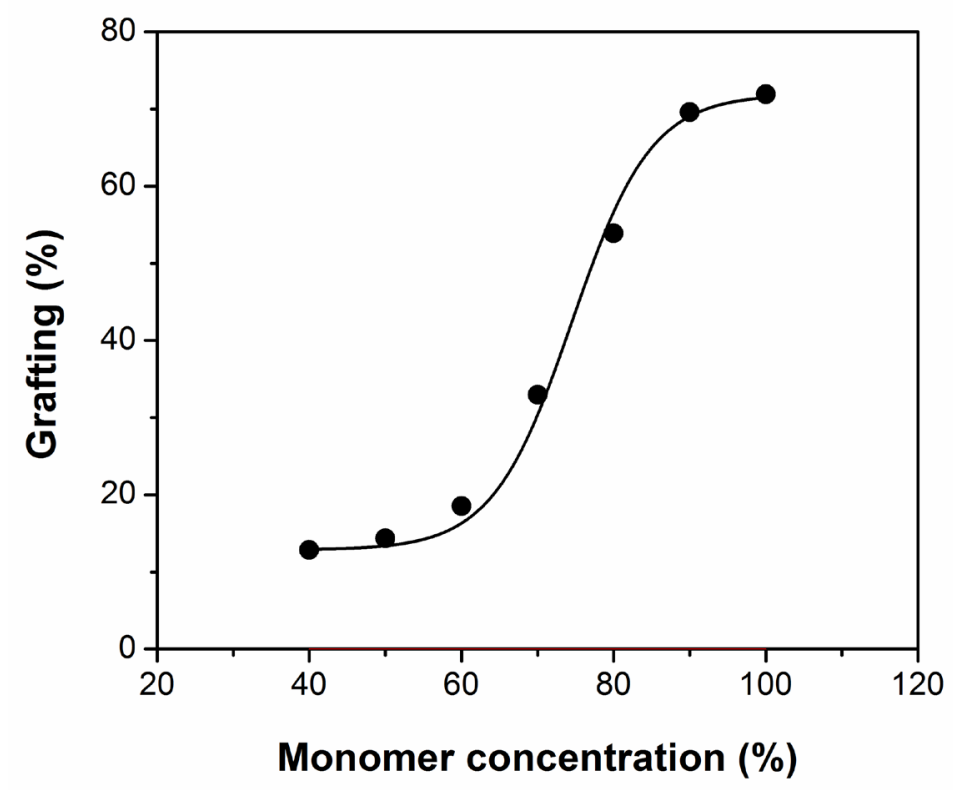

Figure 3. Grafting yield of poly(DEAEMA) onto silicone rubber in toluene as a function of monomer concentration at irradiation dose of $60 \mathrm{kGy}$.

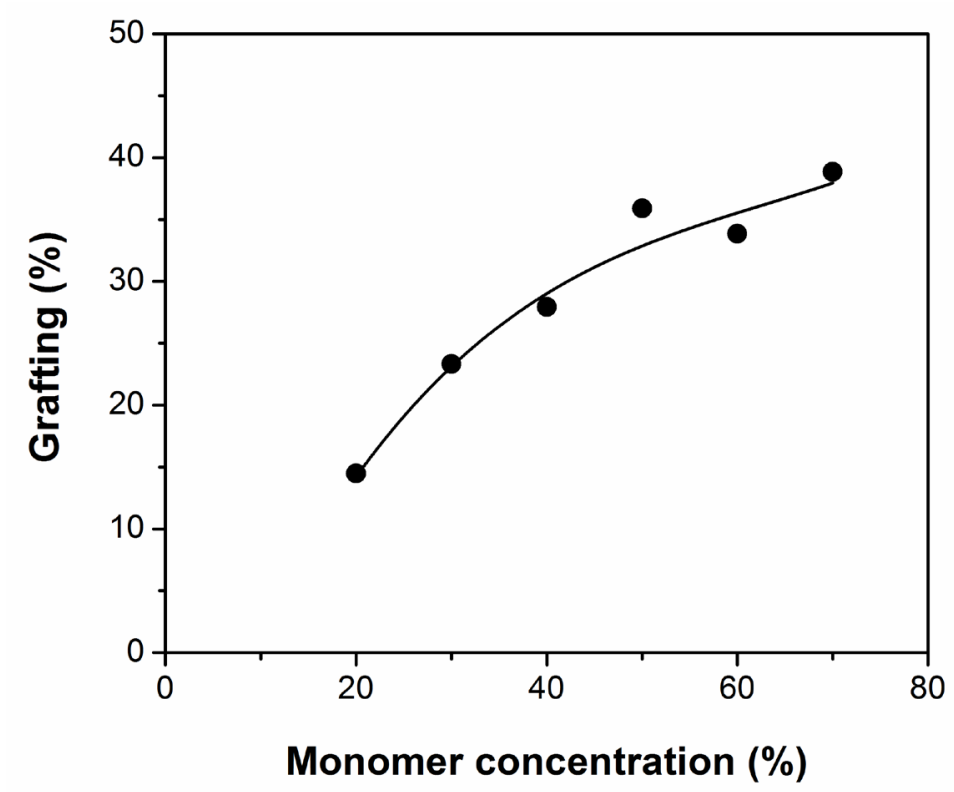

Figure 4. Grafting yield of poly(NVCL) onto SR-g-DEAEMA ${ }_{(11 \% \text { graft })}$ in toluene as a function of monomer concentration at irradiation dose of 60 kGy.

SR-g-DEAEMA (Figure 5(c)) also showed a peak at $1633 \mathrm{~cm}^{-1}$ that belong to the $\mathrm{C}=\mathrm{O}$ from poly(NVCL), and two bands at 2927 and $2856 \mathrm{~cm}^{-1}$ that correspond to the $\mathrm{C}-\mathrm{H}$ stretching vibrations, with these characteristic peaks the grafting of NVCL onto SR was confirmed. Poly(DEAEMA) showed band at $1729 \mathrm{~cm}^{-1}$ for $\mathrm{C}=\mathrm{O}$ (Figure 5(d)); and poly(NVCL) showed carbonyl peak at1622 $\mathrm{cm}^{-1}$ and C-N stretching vibration peak is at 1476 $\mathrm{cm}^{-1}$ (Figure 5(e)).

The thermal transitions for the different systems obtained by DSC are shown in Figure 6. No transitions were observed for SR since its $\mathrm{Tg}\left(-129^{\circ} \mathrm{C}\right.$ ) (Figure 6(a)), poly(DEAEMA) (Figure 6(b)) and SR-g-DEAEMA 72\% graft (Figure 6(c)) showed Tg around 149.2 and $148.5^{\circ} \mathrm{C}$ respectively, (SR-g-DEAEMA $(11 \%$ graft) $)$ - $-\mathrm{NVCL} 14 \%$ 


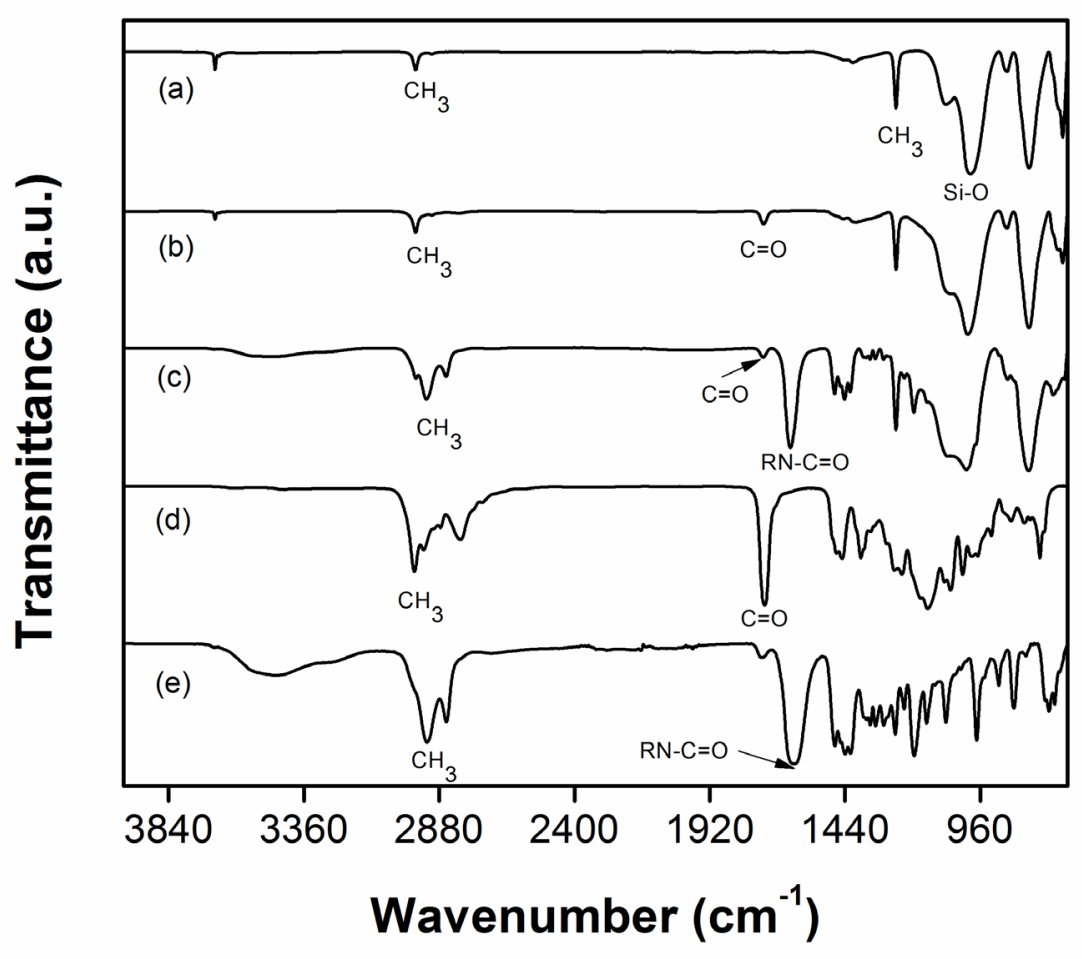

Figure 5. FTIR-ATR spectra of SR pristine (a), SR- $g$-DEAEMA $10 \%$ graft (b), (SR- $g$ DEAEMA $\left._{(12 \% \text { graft })}\right)-g$-NVCL $36 \%$ graft (c), poly(DEAEMA) (d), and poly(NVCL) (e).

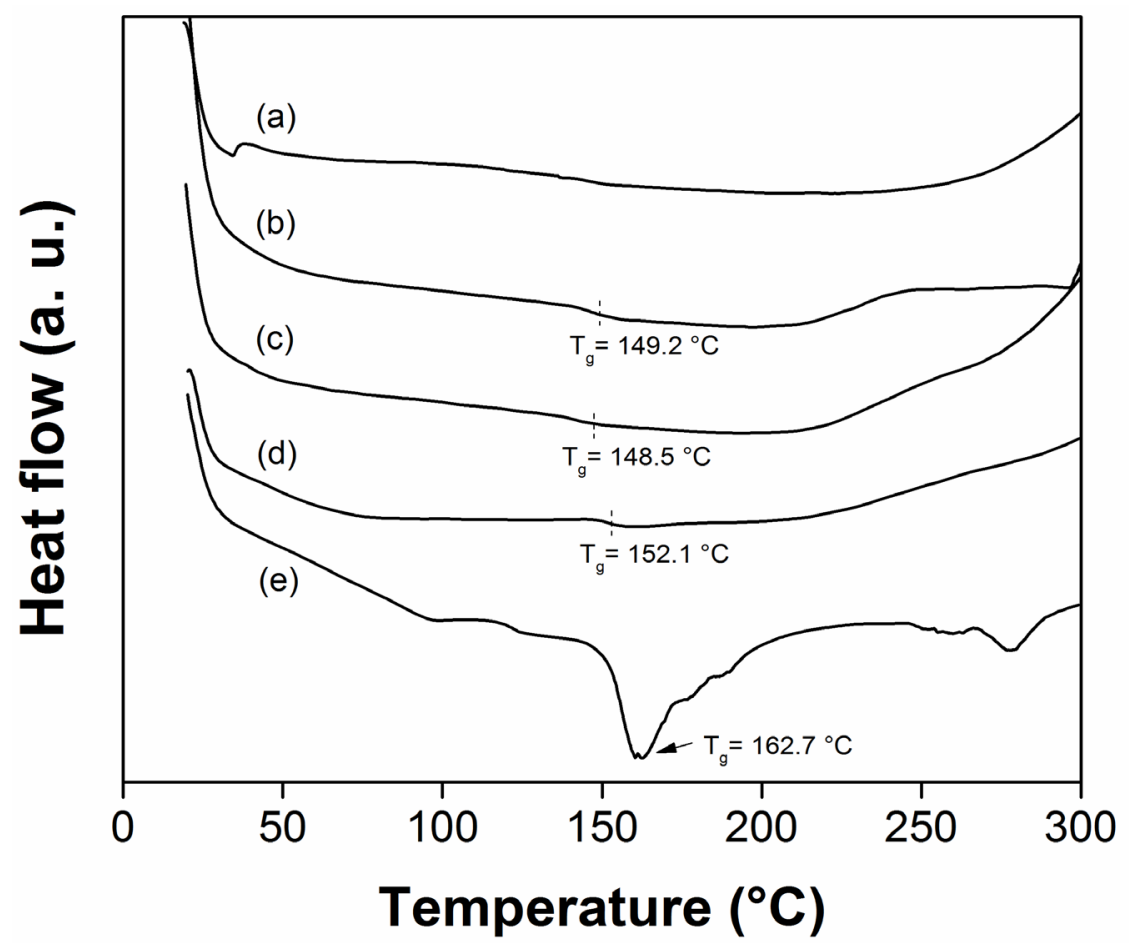

Figure 6. DSC curves for the systems containing DEAEMA and NVCL and grafted onto SR with the respective thermal transition $\left({ }^{\circ} \mathrm{C}\right)$. The thermograms for SR pristine (a), poly(DEAEMA) (b), SR-g-DEAEMA $72 \%$ graft (c), $($ SR- $g$-DEAEMA $(11 \%$ graft $)-g$-NVCL $14 \%$ graft (d), and poly(NVCL) (e). 
graft (Figure 6(d)) presented Tg at $152.1^{\circ} \mathrm{C}$, and poly(NVCL) (Figure 6(e)) exhibited a glass transition temperature at $162.7^{\circ} \mathrm{C}$. These results confirmed that DEAEMA and PNVCL were grafted onto SR rubber with thermal stability at around $155^{\circ} \mathrm{C}$.

Thermal stability was measured by TGA at $10^{\circ} \mathrm{C} \min ^{-1}$ from 25 to $800^{\circ} \mathrm{C}$ and the results are presented in Figure 7 and Table 1. This table contains the thermal decomposition temperatures (10 wt\% loss) and char yield (\%) of the graft copolymers and heteropolymers. The graft copolymers exhibited decreased stability (compared with SR pristine) in $\mathrm{N}_{2}\left(10 \mathrm{wt} \%\right.$ loss at temperatures from 347 to $398^{\circ} \mathrm{C}$ ) as measured by TGA. It is relevant to observe that in several cases, the TGA data were similar (a difference of only $51^{\circ} \mathrm{C}$ ), which could be related either to the thermo-oxidative stability of these polymers or to the thermal weak linkage of DEAEMA and NVCL moieties to SR rubber.

The welling kinetics of the various poly(NVCL)-grafted SR-g-DEMAEMA films immerged in water at $25^{\circ} \mathrm{C}$ was followed by gravimetry. Typical swelling profiles are plotted in Figure 8. Typical diffusion profiles indicate that equilibrium is reached between 800 to $900 \mathrm{~min}$, for graft contents from 14 to $39 \%$ graft. However the initial water diffusion into the outer poly(DEAEMA) and poly(NVCL) layer proceeds at comparable rates.

Figure 9 showed the equilibrium swelling behavior for the films grafted measured as a function of $\mathrm{pH}$ at $25^{\circ} \mathrm{C}$, it was evaluated between 2 and 10. As can be seen, critical $\mathrm{pH}$ point is reached at 3.2, close to pKa of DEAEMA, films were compact at $\mathrm{pH}$ values greater than 11 . At high $\mathrm{pH}$ values, a maximum value of swelling was reached, when the $\mathrm{pH}$ values were lower than 4 , the films were swollen. $\mathrm{pH}$-dependent equilibrium swelling of different

Table 1. Thermogravimetric analysis of the different grafts.

\begin{tabular}{|c|c|c|c|}
\hline Sample & Grafting & $\begin{array}{l}\text { Weight loss temperature } \\
\left(10 \mathrm{wt} \%,{ }^{\circ} \mathrm{C}\right)\end{array}$ & $\%$ Char yield $\left(800^{\circ} \mathrm{C}, \mathrm{N}_{2}\right)$ \\
\hline Poly (DEMAEMA) & --- & 328 & 3.4 \\
\hline SR & --- & 502 & 33.5 \\
\hline SR-g-DEMAEMA & $72 \%$ & 347 & 20.5 \\
\hline (SR-g-DEMAEMA)- $g$-NVCL & $\begin{array}{l}\text { 11\% DEAMEA } \\
14 \% \text { NVCL }\end{array}$ & 398 & 26.6 \\
\hline Poly (NVCL) & --- & 180 & 0.8 \\
\hline
\end{tabular}

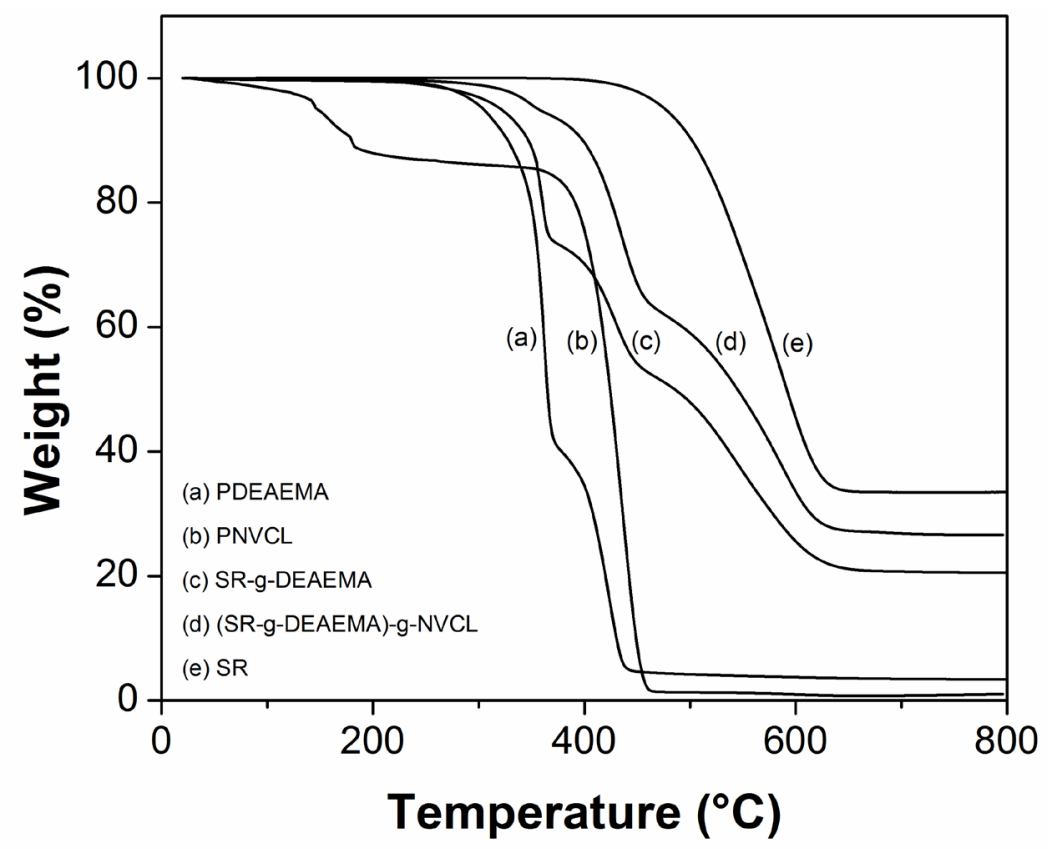

Figure 7. Thermogravimetric analysis of poly(DEAEMA) (a), poly(NVCL) (b), SR-g-DEAEMA 72\% graft (c), (SR-gDEAEMA $\left._{(11 \% \text { graft })}\right)-g$-NVCL 39\% graft (d), and SR pristine (e). 


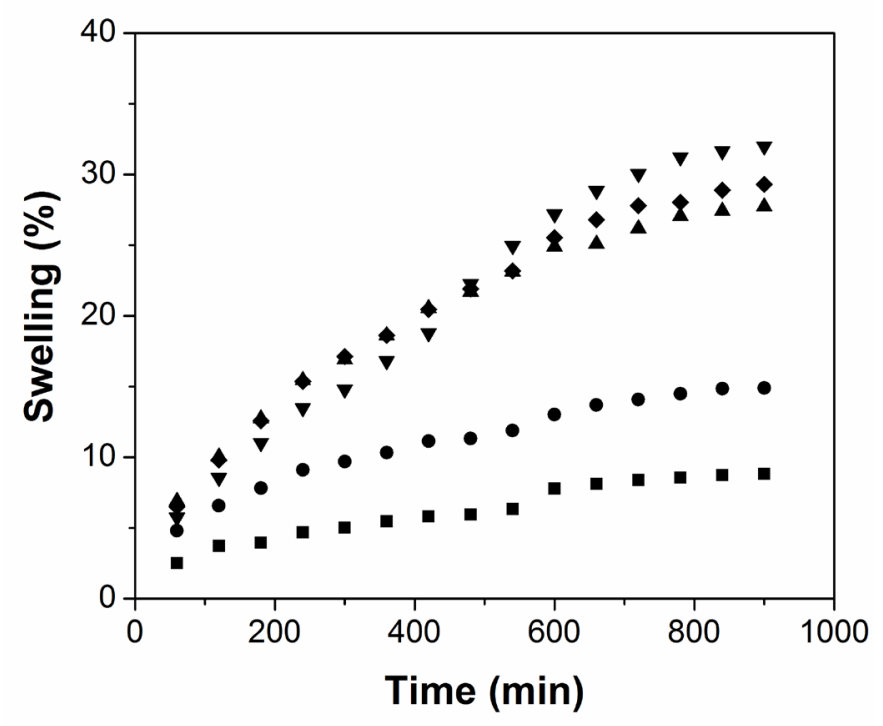

Figure 8. Swelling degree (SR-g-DEAEMA $(11 \%$ graft) $)-g$-NVCL of the different grafts of NVCL in water (at $25^{\circ} \mathrm{C}$ ) as function of time: $14 \%$

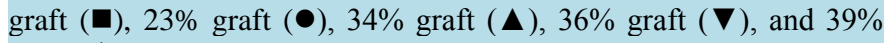
graft $(\bullet)$.

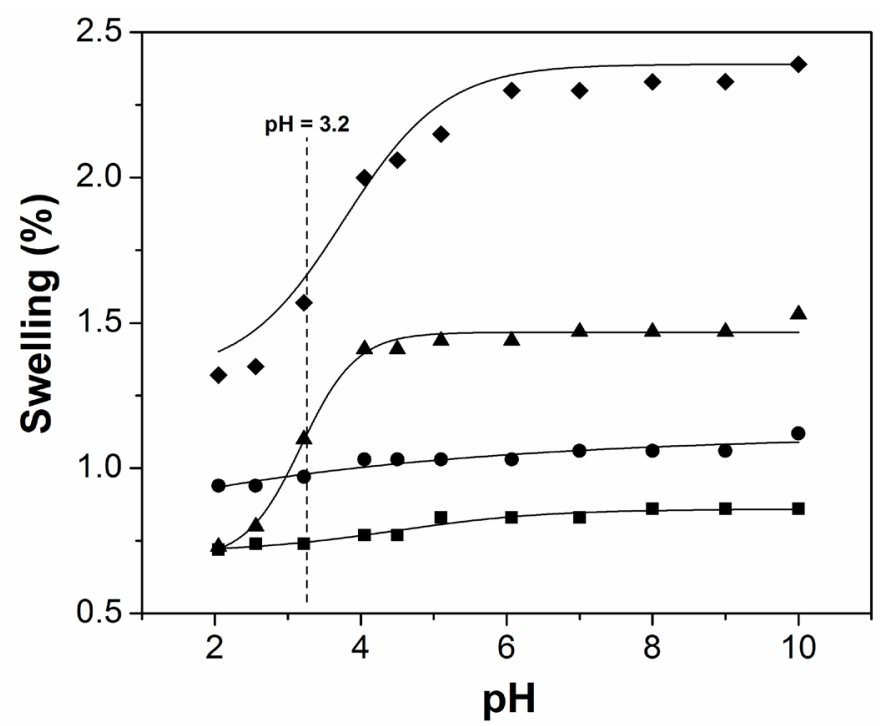

Figure 9. Swelling degree as a function of $\mathrm{pH}$ for SR- $g$-DEAEMA: $10.3 \%$ graft $(\boldsymbol{\square}), 12.8 \%$ graft $(\bullet), 14.3 \%$ graft $(\boldsymbol{\Delta})$, and $13.5 \%$ graft $(\diamond)$.

percentage of poly(DEAMEA) and poly(NVCL) grafted onto SR presented the same critical pH point although the water uptake for the different grafted degree is greater for high grafts than low grafts.

The DSC thermograms of the (SR- $g$-DEAEMA)- $g$-NVCL, which had been previously swollen (24 h) in distilled water, are shown in Figure 10. The onset point of the endothermal peak, determined by the intersecting point of two tangent lines from the baseline and slope of the endothermal peak, was used to establish the LCST of the (SR-g-DEAEMA)-g-NVCL system, which fell between $57.6^{\circ} \mathrm{C}$ and $63.9^{\circ} \mathrm{C}$ for different grafting content.

\section{Conclusion}

A new thermo- and pH-sensitive grafted copolymer of (SR-g-DEAEMA)-g-NVCL was prepared by the direct 


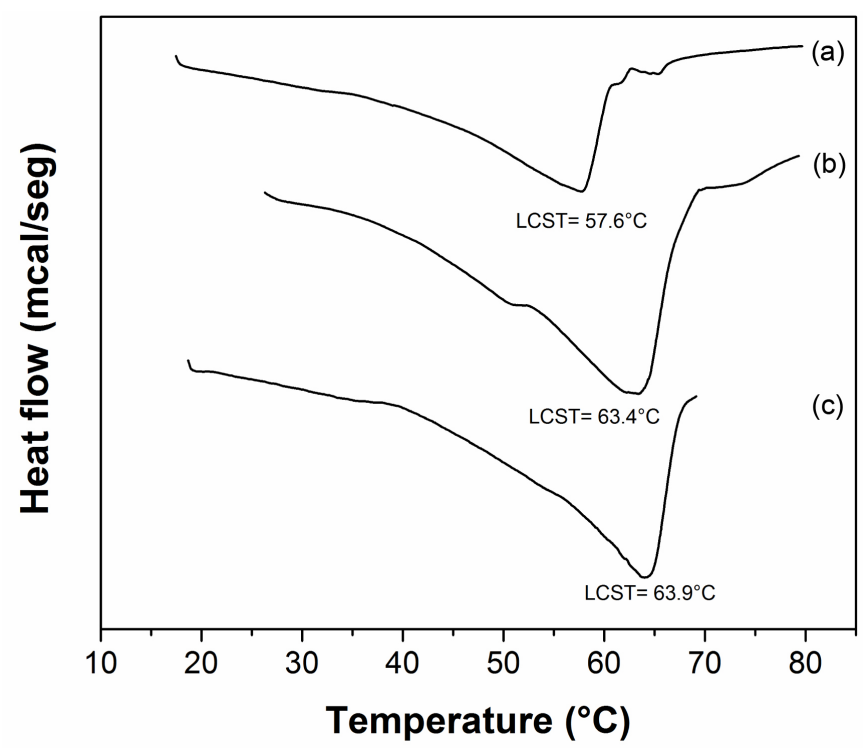

Figure 10. DSC thermograms of water-swelled (SR- $g$-DEAEMA $(11 \%$ graft) $)$ - $g$-NVCL of the different grafts of NVCL: 14\% graft (a), $38 \%$ graft (b), 36\% graft (c). LCST values are shown.

irradiation induced graft polymerization by two-step method. The maximum grafting percentage obtained was $\approx 41 \%$ for a NVCL concentration $50 \mathrm{vol} \%$ and $60 \mathrm{kGy}$ at dose rate of $9.3 \mathrm{kGy} \cdot \mathrm{h}^{-1}$. The optimum grafting dose was from 50 to $60 \mathrm{kGy}$; the monomer concentration could be lower than 80 vol\%. Grafting was confirmed by the FTIR, DSC, TGA, and swelling measurement. LCST around $63.5^{\circ} \mathrm{C}$ was determined by the DSC measurements and $\mathrm{pH}$ critical point observed at 3.2.

\section{Acknowledgements}

Work supported by DGAPA-UNAM Grant IN200714 México and the authors thank B. Leal, M. Cruz, and M. Ham from ICN-UNAM for technical assistance.

\section{References}

[1] Deghiedy, N.M.A. (2004) Synthesis and Characterization of Superabsorbent Hydrogels Based on Natural Polymers Using Ionizing Radiations Thesis National Center for Radiation. National Center for Radiation Research and Technology, Al-Azhar University. https://inis.iaea.org/search/search.aspx?orig_q=RN:43081203

[2] Aramwit, P. (2016) 1-Introduction to Biomaterials for Wound Healing. Wound Healing Biomaterials, Woodhead Publishing, Cambridge, 3-38. http://dx.doi.org/10.1016/B978-1-78242-456-7.00001-5

[3] Williams, D.F. (1986) Definitions in Biomaterials. Consensus Conference of the European Society for Biomaterials. European Society for Biomaterials, Chester, 3-5 March, 1986, 216.

[4] Helsen, J.A. and Missirlis, Y. (2010) Biomaterials-A Tantalus Experience. Springer Heidelberg Dordrecht London New York, Berlin.

[5] Wong, J.Y., Bronzino, J.D. and Peterson, D.R. (2013) Biomaterials_Principles and Practices. 2nd Edition, Vol. 1. Taylor \& Francis Group, Boca Raton.

[6] Bruck, S.D. (1980) Properties of Biomaterials in the Physiological Environment. CRC Press, Boca Raton. http://trove.nla.gov.au/version/10631896

[7] Kato, K., Uchida, E., Kang, T., Uyama, Y. and Ikada, Y. (2003) Polymer Surface with Graft Chains. Progress in Polymer Science, 28, 209-259. http://dx.doi.org/10.1016/S0079-6700(02)00032-1

[8] Ahad, I.U., Bartnik, A., Fiedorowicz, H., Kostecki, J., Korczyc, B., Ciach, T. and Brabazon, D. (2014) Surface Modification of Polymers for Biocompatibility via Exposure to Extreme Ultraviolet Radiation. Journal of Biomedical Materials Research Part A, 102, 3298-3310. http://dx.doi.org/10.1002/jbm.a.34958

[9] Alvarez-Lorenzo, C., Bucio, E., Burillo, G. and Concheiro, A. (2010) Medical Devices Modified at the Surface by Gamma-Ray Grafting for Drug Loading and Delivery. Expert Opinion on Drug Delivery, 7, 173-185. 
http://dx.doi.org/10.1517/17425240903483174

[10] Vahdat, A., Bahrami, H., Ansari, N. and Ziaie, F. (2007) Radiation Grafting of Styrene onto Polypropylene Fibers by a $10 \mathrm{MeV}$ Electron Beam. Radiation Physics and Chemistry, 76, 787-793. http://dx.doi.org/10.1016/j.radphyschem.2006.05.009

[11] Mandal, D.K., Bhunia, H., Bajpai, P.K., Chaudhari, C.V., Dubey, K.A. and Varshney, L. (2016) Radiation-Induced Grafting of Acrylic Acid onto Polypropylene Film and Its Biodegradability. Radiation Physics and Chemistry, 123, 37-45. http://dx.doi.org/10.1016/j.radphyschem.2016.02.011

[12] Ortega, A., Alarcón, D., Muñoz-Muñoz, F., Garzón-Fontecha, A. and Burillo, G. (2015) Radiation Grafting of pHSensitive Acrylic Acid and 4-Vinyl Pyridine onto Nylon-6 Using One- and Two-Step Methods. Radiation Physics and Chemistry, 109, 6-12. http://dx.doi.org/10.1016/j.radphyschem.2014.12.006

[13] Chapiro, A. (1964) Radiation Chemistry of Polymers, Basic Mechanisms in the Radiation Chemistry of Aqueous Media. Radiation Research Supplement, 4, 179-191. http://dx.doi.org/10.2307/3583578

[14] Meléndez-Ortiz, I., Varca, G.H.C., Lugão, A.B. and Bucio, E. (2015) Smart Polymers and Coatings Obtained by Ionizing Radiation: Synthesis and Biomedical Applications. Open Journal of Polymer Chemistry, 5, 17-33. http://dx.doi.org/10.4236/ojpchem.2015.53003

[15] IAEA (2003) Advances in Radiation Chemistry of Polymers. International Atomic Energy Agency, Vienna. http://www-pub.iaea.org/mtcd/publications/pdf/te_1420_web.pdf

[16] Ferraz, C.C., Varca, G.H.C., Ruiz, J.C., Lopes, P.S., Mathor, M.B., Lugão, A.B. and Bucio, E. (2014) RadiationGrafting of Thermo- and pH-Responsive Poly ( $N$-Vinylcaprolactam-Co-Acrylic Acid) onto Silicone Rubber and Polypropylene Films for Biomedical Purposes. Radiation Physics and Chemistry, 97, 298-303. http://dx.doi.org/10.1016/j.radphyschem.2013.12.027

[17] Contreras-García, A., Burillo, G., Aliev, R. and Bucio, E. (2008) Radiation Grafting of N,N’-Dimethylacrylamide and $N$-Isopropylacrylamide onto Polypropylene Films by Two-Step Method. Radiation Physics and Chemistry, 77, 936940. http://dx.doi.org/10.1016/j.radphyschem.2008.02.007

[18] Klouda, L. (2015) Thermoresponsive Hydrogels in Biomedical Applications a Seven-Year Update. European Journal of Pharmaceutics and Biopharmaceutics, 97, 338-349. http://dx.doi.org/10.1016/j.ejpb.2015.05.017

[19] Gutowska, A., Bark, J.S., Kwon, I.C., Bae, Y.H., Cha, Y. and Kim, S.W. (1997) Squeezing Hydrogels for Controlled Oral Drug Delivery. Journal of the Controlled Release, 48, 141-148. http://dx.doi.org/10.1016/S0168-3659(97)00041-2

[20] Lau, A.C.W. and Wu, C. (1999) Thermally Sensitive and Biocompatible Poly ( $N$-Vinylcaprolactam): Synthesis and Characterization of High Molar Mass Linear Chains. Macromolecules, 32, 581-584. http://dx.doi.org/10.1021/ma980850n

[21] Nakabayashi, K. and Mori, H. (2013) Recent Progress in Controlled Radical Polymerization of $N$-Vinyl monomers. European Polymer Journal, 49, 2808-2838. http://dx.doi.org/10.1016/j.eurpolymj.2013.07.006

[22] Valencia-Mora, R.A., Zavala-Lagunes, E. and Bucio, E. (2016) Grafting of Thermo-Sensitive $N$-Vinylcaprolactam onto Silicone Rubber through the Direct Radiation Method. Radiation Physics and Chemistry, 124, 155-158. http://dx.doi.org/10.1016/j.radphyschem.2015.11.003

[23] Cheng, S.C., Feng, W., Pashikin, I.I., Yuan, L.H., Deng, H.C. and Zhou, Y. (2002) Radiation Polymerization of Thermo-Sensitive Poly ( $N$-Vinylcaprolactam). Radiation Physics and Chemistry, 63, 517-519. http://dx.doi.org/10.1016/S0969-806X(01)00638-7

[24] Bütün, V., Billingham, N.C. and Armes, S.P. (1997) Synthesis and Aqueous Solution Properties of Novel Hydrophilic/Hydrophilic Block Copolymers Based on Tertiary Amine Methacrylates and Poly (Ethylene Oxide). Chemical Communications, 7, 671-672. http://dx.doi.org/10.1039/a700772h

[25] Rogero, S.O., Sousa, J.S., Alário, D., Lopérgolo, L. and Lugão, A.B. (2005) Silicone Crosslinked by Ionizing Radiation as Potential Polymeric Matrix for Drug Delivery. Nuclear Instruments \& Methods in Physics Research, 236, 521525. http://dx.doi.org/10.1016/j.nimb.2005.04.031 


\section{Submit or recommend next manuscript to SCIRP and we will provide best service for you:}

Accepting pre-submission inquiries through Email, Facebook, LinkedIn, Twitter, etc.

A wide selection of journals (inclusive of 9 subjects, more than 200 journals)

Providing 24-hour high-quality service

User-friendly online submission system

Fair and swift peer-review system

Efficient typesetting and proofreading procedure

Display of the result of downloads and visits, as well as the number of cited articles

Maximum dissemination of your research work

Submit your manuscript at: http://papersubmission.scirp.org/ 